\title{
Spatio-temporal changes in agricultural hydro- thermal conditions in China from 1951 to 2010
}

\author{
CUI Yaoping, NING Xiaoju, "QIN Yaochen, LI Xu, CHEN Youmin
}

College of Environment and Planning, Key Laboratory of Geospatial Technology for Middle and Lower Yellow River Regions, Henan Collaborative Innovation Center for Coordinating Industrialization, Urbanization and Modernization in Center Economic Zone, Henan University, Kaifeng 475004, Henan, China

\begin{abstract}
Based on the daily observation data of 824 meteorological stations during 19512010 released by the National Meteorological Information Center, this paper evaluated the changes in the heat and moisture conditions of crop growth. An average value of ten years was used to analyze the spatio-temporal variation in the agricultural hydrothermal conditions within a $1 \mathrm{~km}^{2}$ grid. Next, the inter-annual changing trend was simulated by regression analysis of the agricultural hydrothermal conditions. The results showed that the contour lines for temperature and accumulated temperatures (the daily mean temperature $\geq 0^{\circ} \mathrm{C}$ ) increased significantly in most parts of China, and that the temperature contour lines had all moved northwards over the past 60 years. At the same time, the annual precipitation showed a decreasing trend, though more than half of the meteorological stations did not pass the significance test. However, the mean temperatures in the hottest month and the coldest month exhibited a decreasing trend from 1951 to 2010 . In addition, the $0^{\circ} \mathrm{C}$ contour line gradually moved from the Qinling Mountains and Huaihe River Basin to the Yellow River Basin. All these changes would have a significant impact on the distribution of crops and farming systems. Although the mechanisms influencing the interactive temperature and precipitation changes on crops were complex and hard to distinguish, the fact remained that these changes would directly cause corresponding changes in crop characteristics.
\end{abstract}

Keywords: temperature; precipitation; accumulated temperature; agricultural condition; China

\section{Introduction}

Global warming and precipitation change lead to various oscillations of natural systems, ecosystems, human health and other aspects. Especially, agricultural production systems, which evidently rely on climatic resources, show an obvious frangibility and vulnerability (Burton et al., 2002; Ragab and Prudhomme, 2002; Fernanda and Maria, 2009; Alam et al.,

Received: 2015-12-29 Accepted: 2016-02-01

Foundation: National Basic Program of China (973 Program), No.2012CB955800; National Natural Science Foundation of China, No.41171438, No.41401504

Author: Cui Yaoping (1984-) specialized in land use and climate change, E-mail: cuiyp@1reis.ac.cn; Ning Xiaoju (1987-) specialized in sustainable development, E-mail: nxj0655@163.com. Both of the authors had the same contributions to the paper.

"Corresponding author: Qin Yaochen (1959-), Professor, specialized in a regional model on sustainable development and geographic information science. E-mail: qinyc@henu.edu.cn 
2013). Climatic factors determine potential agricultural productivity. Global warming will continue to increase the heat stress on major crops worldwide, which, coupled with the instability caused by precipitation, can cause a threat to current crop production (Ramirez-Villegas et al., 2013). Edmar et al. (2013) found that crop areas will evidently change in 2071-2100, whereby the area changes for corn and wheat crops would be more intense than those for rice and soybean crops within the context of changes in heat stress associated with A1B emission scenarios. However, certain studies have shown that rice planting may face greater risk in the future (Ramirez-Villegas et al., 2013). For certain specific areas, studies have revealed that agricultural planting regions at $40^{\circ}-60^{\circ} \mathrm{N}$ would face more risk in the future. At the same time, high-latitude agricultural regions, such as those in northern Europe and Canada, would benefit (Olesen and Bindi, 2002; Falloon and Betts, 2010; Smitha et al., 2013).

An analysis of the changes in agricultural conditions is indispensable for exploring agricultural adaptability to climate change in China. Therefore, many studies have focused on this topic. The annual average temperature in China has increased by $0.4-0.5^{\circ} \mathrm{C}$ per century under the background of global change (Ding et al., 2003), and precipitation has also been shown to exhibit obvious regional characteristics (Piao et al., 2010). From 1960 to 2013, precipitation in most parts of China tended to be normal or stable, which was beneficial to human activities (Liu et al., 2015). Specifically, the climate presented a warming trend in southern China and the Hanjiang basin (Li et al., 2010; Chen et al., 2006). A drought trend then developed in southern China while a moisture trend occurred in the southeast region (Ren et al., 2014). Moreover, in some provinces of northern China, such as Shandong province, the number of precipitation days showed a significantly decreasing trend (Dong et al., 2014). In northwest China, the warming trend in winter was more intense than in summer. In addition, the east and west parts of northwest China showed a warm-wet trend and warm-dry trend, respectively (Liu et al., 2005). On the one hand, such temperature and precipitation changes would have a profound impact on China's agricultural production. Firstly, the increasing accumulated temperature-over $10^{\circ} \mathrm{C}$ in some southern provinces - caused an expansion of the boundaries of tropical crop planting towards high-altitude areas (Dai et al., 2014). In addition, the increasing precipitation in the growing season of rice has led to an improved growth pattern in the main rice-growing regions of China (Ma et al., 2012). Moreover, Tao et al. (2012) thought that climate change changed the phenology of wheat in China. The interaction between the decreasing negative accumulated temperature and mean temperature in the coldest month and the increasing annual extreme minimum temperature has enlarged the growth areas of winter wheat (Qian et al., 2014). Some studies have found that the rising winter temperature has led to the northern boundary of winter wheat being extended significantly - by $70 \mathrm{~km}$ over the past 50 years (Hu et al., 2014). Furthermore, the increasing light and heat resources in the northwest region have been shown to increase the light/temperature production potential of cotton (Mamat et al., 2014). On the other hand, the change in temperature and precipitation may lead to more negative consequences for agricultural production. Han et al. considered that the drought disaster in southwest China over the past 60 years had been mainly caused by rising temperatures (Han et al., 2014). Xiong et al. (2013) found that many climatic factors, such as the average temperature, daily temperature and radiation, had significantly changed in the period of rice growth from 1981 to 2007. 
Additionally, the increasing maximum temperature would lead to a corresponding increase in heat damage in rice production. In terms of northern regions, some studies have found that the drought trend was aggravated in Huang-Huai-Hai Plain in China from 1991 to 2011, and that the climate suitability of summer maize also declined (Xu et al., 2014a, 2014b).

Obviously, under the background of global climate change, the climatic conditions will change correspondingly in China. But what are the specific characteristics of different periods in different regions? To answer this question, this study selected the climate indicators closely related to agricultural production so as to analyze the spatio-temporal changes in agricultural climate conditions based on the daily meteorological observation data over a 60 -year period and to compare the changing trend in water and heat resources required for crop growth.

\section{Data and methods}

\subsection{Climatic factors}

This study considers how temperature and precipitation directly affect crop growth. Therefore, five climatic factors were chosen to analyze spatio-temporal changes in agricultural hydrothermal conditions. The annual mean temperature was used to reflect the general changing trend in temperature, and the mean temperature in the hottest month and mean temperature in the coldest month were used to reflect changes in extreme temperature in this study. Also, the mean temperature in the hottest month was used to represent the requirements of high temperature in agricultural production. We defined accumulated temperature as the sum by which the actual air temperature rises above a given threshold value and the number of days during which this increase is maintained. The accumulated temperature over $0^{\circ} \mathrm{C}$ was used to represent the change in heat resources within a defined period of field-farming activity. The mean temperature in the coldest month was used to reflect the effect of climate change on winter crop conditions. Lastly, the annual precipitation was used to represent the variety of water sources required for crop growth. All of the above mentioned climatic factors jointly determine the climatic conditions for crop growth.

\subsection{Data and process}

In this study, daily observation data from 1951 to 2010 from 824 meteorological stations were collected. In accordance with the introductory documentation of the China Meteorological Data Sharing Service System, we used SQL language to calculate the annual mean temperature, the mean temperature in the hottest month, the mean temperature in the coldest month, and the annual precipitation. Finally, based on the rule that the accumulated temperature onset and offset are defined according to consecutive days (more than 5 days), the accumulated temperature over $0^{\circ} \mathrm{C}$ was recorded.

According to the previous research, we found that the spatial interpolation for temperature based on a DEM (digital elevation model) can simulate the spatial distribution of temperature effectively (He et al., 2005; Ji and Yu, 2010; Li et al., 2014). Here, the study uses the DEM as a co-variable and employs the ordinary Kriging method to interpolate the temperature and precipitation data. The final Kriging interpolation outputs were $1 \mathrm{~km} * 1 \mathrm{~km}$ grid data. 
In the actual processing, climatic factors were divided into six averaged data groups using ArcGIS 10.3 software: namely 1950s, 1960s, 1970s, 1980s, 1990s and 2000s. Referring to Wei's research (Wei, 2007), a linear regression method was used to estimate the linear tendency of different climatic factors. Also, the F-test was used to determine the significance level (with an $F$ value of 0.1 ).

\section{Results and analysis}

\subsection{Interpolation accuracy}

According to the results of Kriging interpolation models used in previous studies ( $\mathrm{Ji}$ and $\mathrm{Yu}$, 2010), the spherical model was used to interpolate. The mean error of prediction and the standard root mean square error were used to perform the entire cross-examination. The values of the mean error and the standard root mean square error were close to 0 and 1 respectively, indicating improved interpolation accuracy (Tang and Yang, 2012). The results showed that the interpolation accuracy achieved in the 1950s provided the lowest level of accuracy because observation stations in the 1950s were relatively rare among the six averaged data groups. In terms of the different interpolation accuracies of the climatic factors, the error mean of prediction and the standard root mean square error of the mean temperature in the coldest month were, respectively, close to 0 and 1, indicating a significantly high level of interpolation accuracy. In terms of the other climatic factors-accumulated temperature over $0^{\circ} \mathrm{C}$ and annual precipitation-although the standard root mean square error of the two factors was close to 1 , the mean error deviated from 0 relatively (Table 1 ). The insensitive relationship between the two climatic factors and the DEM may have led to these results. Moreover, it was difficult to estimate the complex spatial relationships between the two climatic factors and other environmental elements, such as vegetation and slope, using the interpolation model.

Table 1 Cross-examination accuracy of interpolation methods

\begin{tabular}{clcccccc}
\hline Climatic factor & \multicolumn{1}{c}{ Examination } & $1950 \mathrm{~s}$ & $1960 \mathrm{~s}$ & $1970 \mathrm{~s}$ & $1980 \mathrm{~s}$ & $1990 \mathrm{~s}$ & $2000 \mathrm{~s}$ \\
\hline $\begin{array}{c}\text { Annual mean } \\
\text { temperature }\end{array}$ & Mean error of prediction & 0.025 & 0.027 & 0.023 & 0.023 & 0.028 & 0.027 \\
& Standard root mean square error & 1.864 & 1.284 & 1.382 & 1.433 & 1.376 & 1.405 \\
\hline $\begin{array}{c}\text { Mean temperature in the } \\
\text { hottest month }\end{array}$ & Mean error of prediction & 0.016 & 0.021 & 0.019 & 0.020 & 0.016 & 0.017 \\
& Standard root mean square error & 1.293 & 1.486 & 1.378 & 1.505 & 1.225 & 1.306 \\
\hline $\begin{array}{c}\text { Mean temperature in the } \\
\text { coldest month }\end{array}$ & Mean error of prediction & 0.023 & 0.026 & 0.021 & 0.026 & 0.036 & 0.036 \\
\hline $\begin{array}{c}\text { Accumulated tempera- } \\
\text { ture over 0 }{ }^{\circ} \mathrm{C}\end{array}$ & Standard root mean square error & 1.283 & 0.938 & 0.095 & 0.982 & 1.088 & 1.085 \\
\hline \multirow{2}{*}{$\begin{array}{c}\text { Annual precipitation } \\
\text { Mnean error of prediction }\end{array}$} & 4.586 & 5.184 & 4.589 & 4.692 & 3.896 & 4.104 \\
& Standard root mean square error & 1.92 & 1.298 & 1.37 & 1.412 & 1.372 & 1.421 \\
\hline
\end{tabular}

\subsection{Temporal variation in agricultural climatic factors}

By comparing the decadal mean values of the six data groups separately, the fluctuant values of all climatic factors were obtained (Figure 1). The decadal mean values for the annual 
mean temperature, mean temperature in the coldest month and accumulated temperature over $0^{\circ} \mathrm{C}$ from the 1950 s to 1970 s were all lower than the average value for all 60 years. However, for the remaining decades (1980 to 2000), the decadal mean values for the three climatic factors showed an increasing tendency to be higher than the average value for all 60 years, especially for the mean values of accumulated temperature over $0^{\circ} \mathrm{C}$. The letter $\mathrm{U}$ characteristics were found for the mean temperature in the hottest month. The annual precipitation showed a typical fluctuation trend along with time, and no significant change patterns have been found. The statistical characteristics relating to the agricultural climatic factors provided key information among temporal variations (Table 2). Based on the consideration of heat and water supply for crops, we found that the variation coefficient of
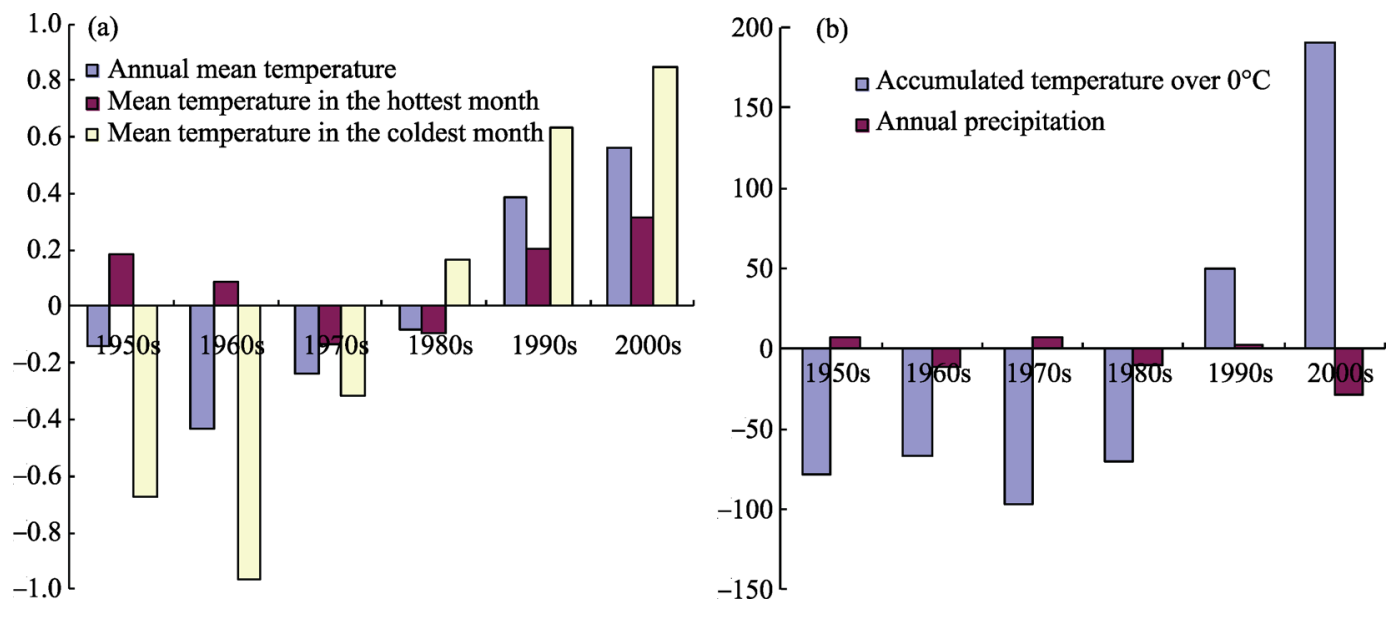

Figure 1 Decadal changes in agricultural climatic factors in China

Table 2 The statistical characteristics of agricultural climatic factors

\begin{tabular}{|c|c|c|c|c|c|c|c|}
\hline Climatic factors & $\begin{array}{l}\text { Statistical } \\
\text { factors }\end{array}$ & $1950 \mathrm{~s}$ & $1960 \mathrm{~s}$ & $1970 \mathrm{~s}$ & $1980 \mathrm{~s}$ & $1990 \mathrm{~s}$ & $2000 \mathrm{~s}$ \\
\hline \multirow{2}{*}{$\begin{array}{l}\text { Annual mean } \\
\text { temperature }\end{array}$} & $\begin{array}{l}\text { Standard } \\
\text { deviation }\end{array}$ & 6.7 & 6.7 & 6.7 & 6.6 & 6.5 & 6.5 \\
\hline & $\begin{array}{l}\text { Coefficient of } \\
\text { variation }\end{array}$ & 0.6 & 0.6 & 0.6 & 0.6 & 0.5 & 0.5 \\
\hline \multirow{2}{*}{$\begin{array}{l}\text { Mean temperature } \\
\text { in the hottest month }\end{array}$} & $\begin{array}{l}\text { Standard } \\
\text { deviation }\end{array}$ & 4.9 & 5.1 & 5.1 & 5.0 & 4.9 & 4.8 \\
\hline & $\begin{array}{l}\text { Coefficient of } \\
\text { variation }\end{array}$ & 0.2 & 0.2 & 0.2 & 0.2 & 0.2 & 0.2 \\
\hline \multirow{2}{*}{$\begin{array}{l}\text { Mean temperature } \\
\text { in the coldest month }\end{array}$} & $\begin{array}{l}\text { Standard } \\
\text { deviation }\end{array}$ & 10.6 & 10.1 & 10.2 & 10.2 & 10.1 & 10.1 \\
\hline & $\begin{array}{l}\text { Coefficient of } \\
\text { variation }\end{array}$ & -3.1 & -2.7 & -3.3 & -3.9 & -4.7 & -5.2 \\
\hline \multirow{2}{*}{$\begin{array}{c}\text { Accumulated } \\
\text { temperature over } 0^{\circ} \mathrm{C}\end{array}$} & $\begin{array}{l}\text { Standard } \\
\text { deviation }\end{array}$ & 1798 & 1795 & 1825 & 1814 & 1824 & 1831 \\
\hline & $\begin{array}{l}\text { Coefficient of } \\
\text { variation }\end{array}$ & 0.4 & 0.4 & 0.4 & 0.4 & 0.4 & 0.4 \\
\hline \multirow{2}{*}{ Annual precipitation } & $\begin{array}{l}\text { Standard } \\
\text { deviation }\end{array}$ & 545.5 & 527 & 550 & 541 & 572.3 & 529 \\
\hline & $\begin{array}{l}\text { Coefficient of } \\
\text { variation }\end{array}$ & 0.6 & 0.6 & 0.6 & 0.6 & 0.7 & 0.6 \\
\hline
\end{tabular}


accumulated temperature over $0^{\circ} \mathrm{C}$ and the annual precipitation were relatively stable at 0.4 and $0.6-0.7$, respectively, indicating that the fluctuation frequency of the two climatic factors was relatively stable throughout the study period.

\subsection{Spatio-temporal variation in temperature}

(1) Annual mean temperature

Based on the spatial distribution of annual mean temperature (Figure 2), the $20^{\circ} \mathrm{C}$ contour lines in certain southern regions extended northwards. The $15^{\circ} \mathrm{C}$ contour line had moved from the Huaihe River Basin to the Yellow River Basin, while the regions of the $10^{\circ} \mathrm{C}$ contour line remained relatively stable. In the northeast region, the areas of frozen soil zones with an annual mean temperature below $0^{\circ} \mathrm{C}$ markedly diminished. In the Qinghai-Tibet Plateau, although the areas of frozen soil zones with an annual mean temperature below $0^{\circ} \mathrm{C}$ increased initially then decreased, the final results showed that the areas within the Qinghai-Tibet Plateau have diminished over the past 60 years. At the same time, some patches with an annual mean temperature of $5-10^{\circ} \mathrm{C}$ were found within the Qaidam Basin. Generally, the contour lines of increasing annual mean temperature were repositioned towards north, and the areas of increasing temperature expanded during the study period.

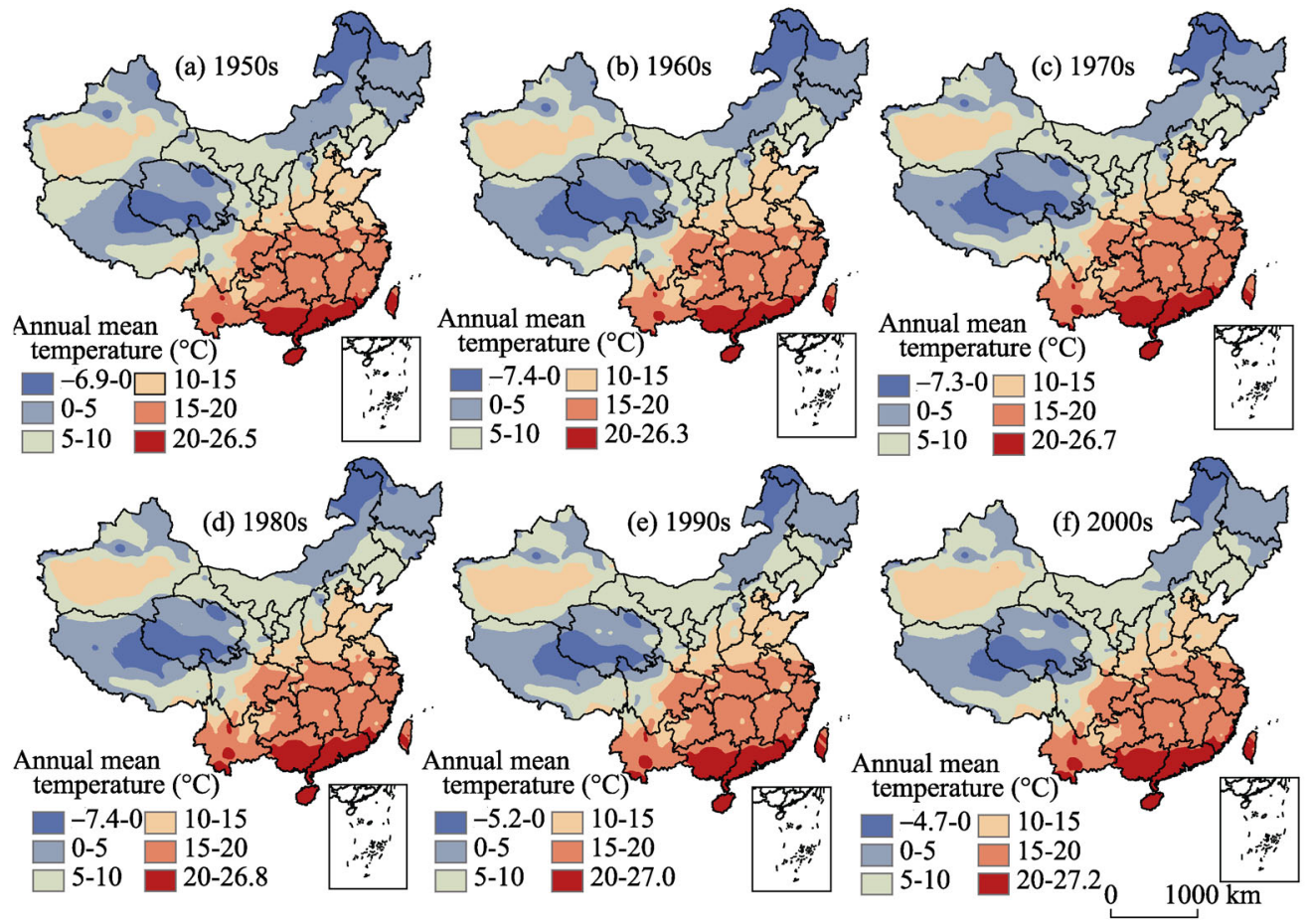

Figure 2 Spatial interpolation results of mean temperature in China from 1951 to 2010

Comparing the temperature change of the earlier decadal data with the later decadal data, the analysis results illustrated that different change patterns were apparent in different regions. Therein, in the 1960s (Figure 3a), the decadal annual mean temperature in most parts of China decreased by $0-2.5^{\circ} \mathrm{C}$, while the areas with an increasing temperature trend mainly involved northern Xinjiang and eastern Inner Mongolia. In the 1970s (Figure 3b), the tem- 
perature in most areas (86.5\% of China as a whole) showed an increasing trend. In the $1980 \mathrm{~s}$ (Figure 3c), $72.3 \%$ of the entire area exhibited an increasing trend, while the regions with a decreasing trend mainly involved the Sichuan Basin, Guanzhong plain and Huang-Huai-Hai Plain. In the 1990s (Figure 3d), almost all areas in China (98\%) showed an increasing trend. In the 2000s (Figure 3e), there was a reduction in areas showing an increasing trend, with a whole-area rate of $70.7 \%$, mainly involving regions within northern China. The statistical characteristics of regression analysis and the significance test also showed that the trend value $b$ was increased in almost all meteorological observation stations, and more than $86.0 \%$ of observation stations passed the significance test (Table 3 ).

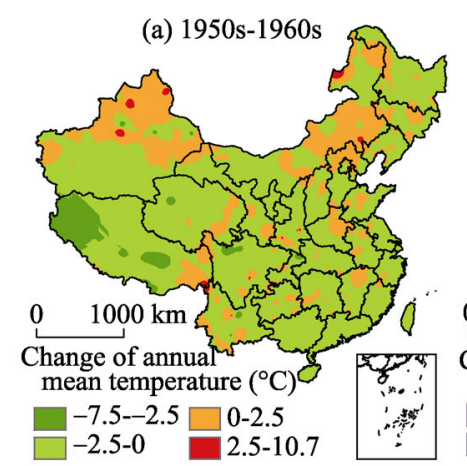

(d) $1980 \mathrm{~s}-1990 \mathrm{~s}$

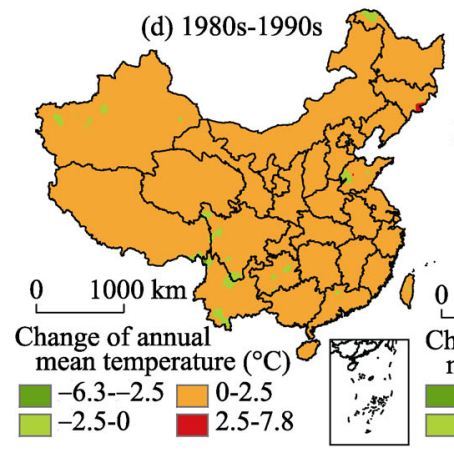

(b) $1960 \mathrm{~s}-1970 \mathrm{~s}$

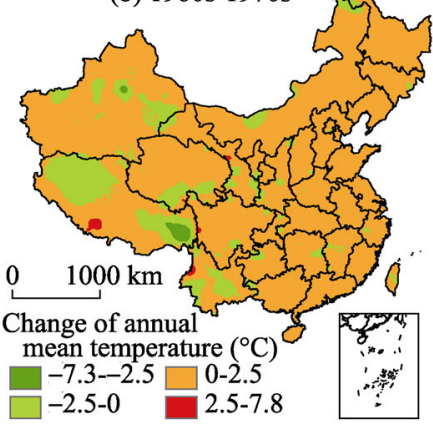

(e) $1990 \mathrm{~s}-2000 \mathrm{~s}$

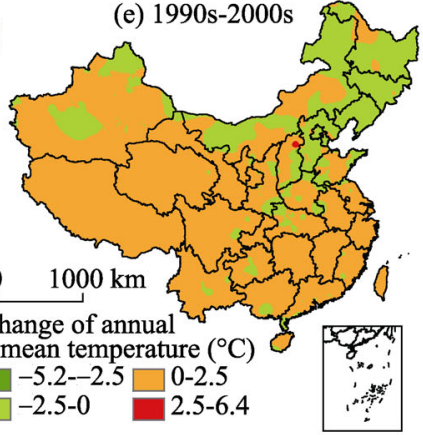

(c) $1970 \mathrm{~s}-1980 \mathrm{~s}$

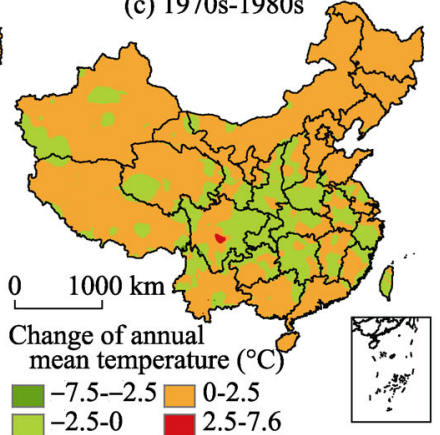

Figure 3 Spatial changing trend of mean temperature in China over the past 60 years

Table 3 The statistical characteristics of regression analysis and significance test

\begin{tabular}{|c|c|c|c|c|}
\hline Percentage / \% & $\begin{array}{l}\text { Regression coeffi- } \\
\text { cients } b>0 \text { and } f \\
\text { (significance) }\end{array}$ & $\begin{array}{l}\text { Regression coeffi- } \\
\text { cients } b>0 \text { and } f \text { (non } \\
\text { significance) }\end{array}$ & $\begin{array}{l}\text { Regression coeffi- } \\
\text { cients } b<0 \text { and } f \\
\text { (significance) }\end{array}$ & $\begin{array}{c}\text { Regression coeffi- } \\
\text { cients } b<0 \text { and } f \\
\text { (non significance) }\end{array}$ \\
\hline $\begin{array}{l}\text { Annual mean } \\
\text { temperature }\end{array}$ & 85.94 & 0.86 & 10.15 & 3.06 \\
\hline $\begin{array}{l}\text { Mean temperature in } \\
\text { the hottest month }\end{array}$ & 34.19 & 10.17 & 31.86 & 23.77 \\
\hline $\begin{array}{l}\text { Mean temperature in } \\
\text { the coldest month }\end{array}$ & 81.94 & 0.12 & 16.09 & 1.84 \\
\hline $\begin{array}{l}\text { Accumulated tem- } \\
\text { perature over } 0^{\circ} \mathrm{C}\end{array}$ & 86.32 & 0.49 & 11.11 & 2.08 \\
\hline Annual precipitation & 6.72 & 10.87 & 35.53 & 46.89 \\
\hline
\end{tabular}

(2) Accumulated temperature over $0^{\circ} \mathrm{C}$

Based on spatial changes of the six accumulated data groups, the results (Figure 4) 
showed that the $8000^{\circ} \mathrm{C}$ contour lines of accumulated temperature over $0^{\circ} \mathrm{C}$ had extended into southern China. The $6000^{\circ} \mathrm{C}$ contour lines of accumulated temperature over $0^{\circ} \mathrm{C}$ had gradually moved from south to north and crossed the Yangtze River. In the western regions of Inner Mongolia, the areas with $4000-6000^{\circ} \mathrm{C}$ of accumulated temperature over $0^{\circ} \mathrm{C}$ had become considerably more widespread over the past 60 years. Some regions in the Qinghai-Tibet Plateau had changed from $2000^{\circ} \mathrm{C}$ of accumulated temperature over $0^{\circ} \mathrm{C}$ to $2000-4000^{\circ} \mathrm{C}$.
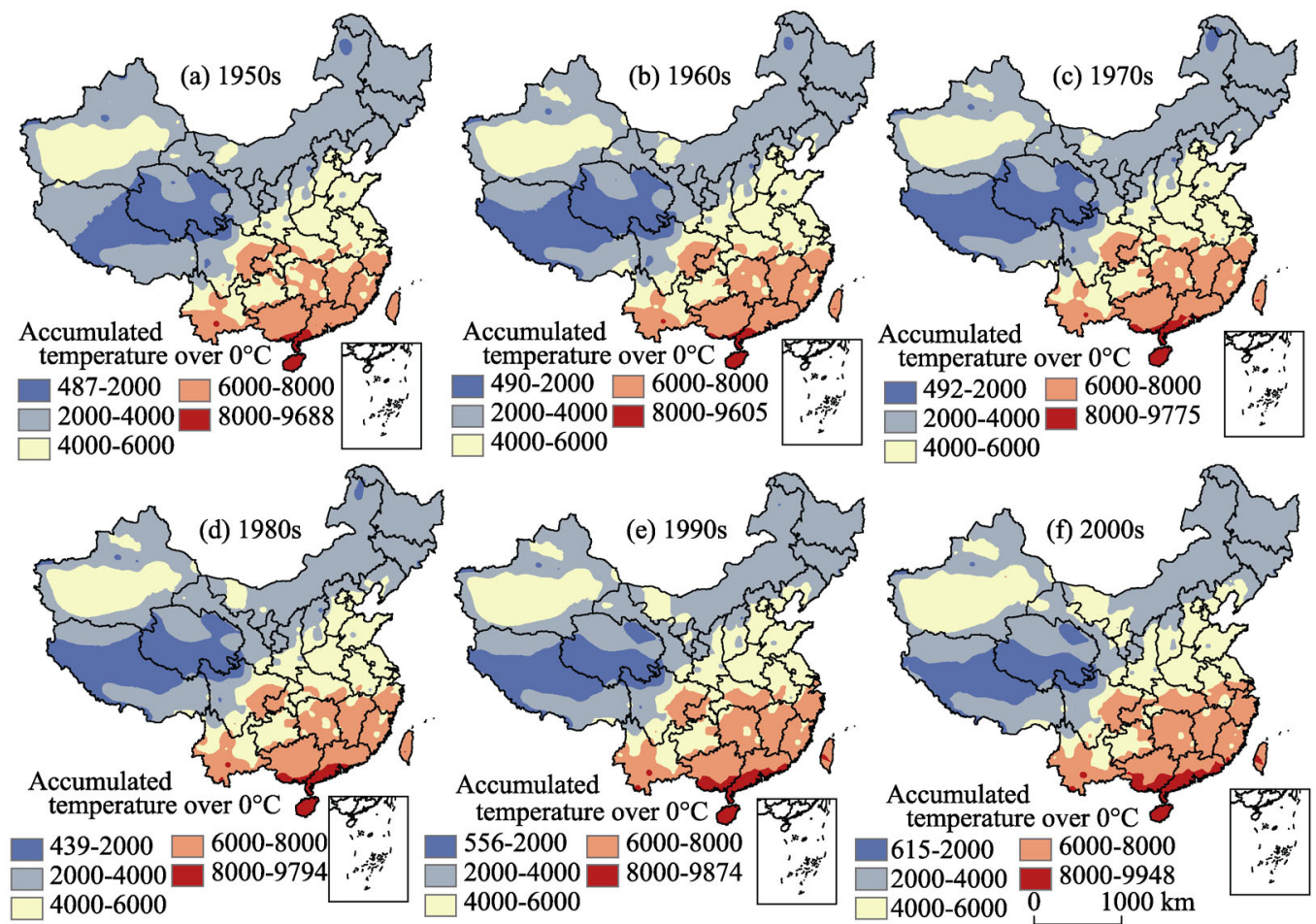

Figure 4 Spatial interpolation results of the accumulated temperatures over $0^{\circ} \mathrm{C}$ in China from 1951 to 2010

The main change range of accumulated temperature over $0^{\circ} \mathrm{C}$ was from $0^{\circ} \mathrm{C}$ to $250^{\circ} \mathrm{C}$ (Figure 5). From the 1960s to the 1980s, the regions with increasing or decreasing trends occupied a huge total area of China. After 1990 , the accumulated temperature over $0^{\circ} \mathrm{C}$ showed a significant pattern-namely, almost all regions exhibited an increasing trend. In the $1960 \mathrm{~s}$ and $1970 \mathrm{~s}, 58.7 \%$ and $44.7 \%$ of areas, respectively, showed an increasing trend. In the 1980 s, $63.4 \%$ of areas showed an increasing trend-exceeding $60 \%$ for the first time. In the 1990s and 2000s, more than $95.0 \%$ of areas showed an increasing trend. All changes in spatial distributions for different decades are shown in Figure 5. The statistical characteristic results of regression analysis and significance tests showed that the trend value $b$ was more than 0 in almost all meteorological observation stations, and only $0.5 \%$ of observation stations did not pass the significance test (Table 3).

(3) Mean temperature in the hottest month and the coldest month

The patterns of temperature change were revealed not only by annual mean temperature and accumulated temperature, but also by the mean temperature in the hottest and coldest month. 
(a) $1950 \mathrm{~s}-1960 \mathrm{~s}$

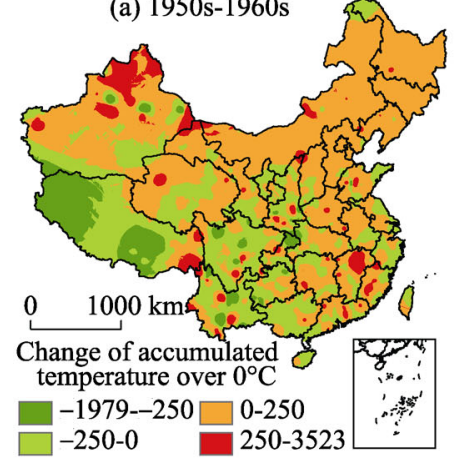

(d) $1980 \mathrm{~s}-1990 \mathrm{~s}$

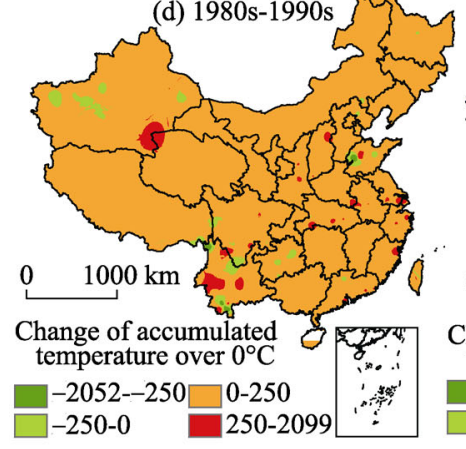

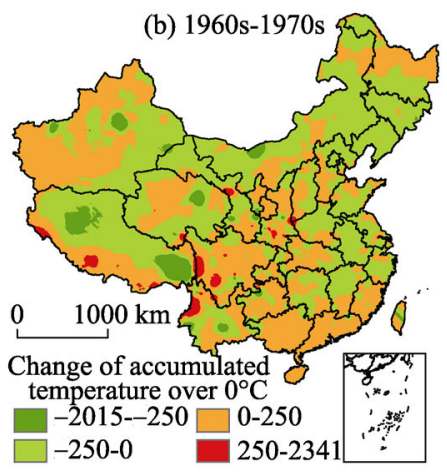

(e) $1990 \mathrm{~s}-2000 \mathrm{~s}$

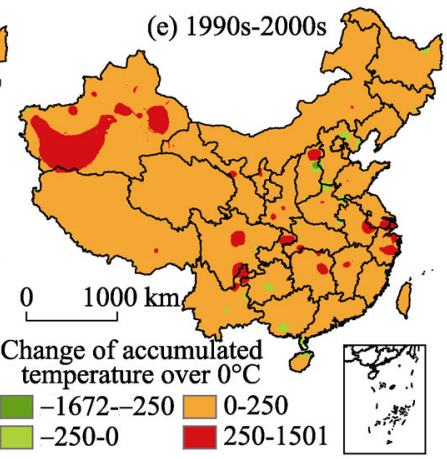

(c) $1970 \mathrm{~s}-1980 \mathrm{~s}$

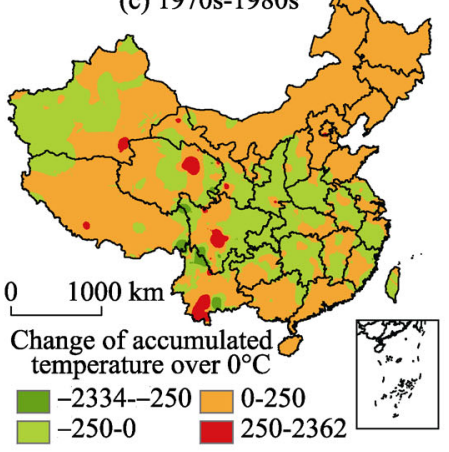

Figure 5 Spatial changing trend of the accumulated temperatures over $0^{\circ} \mathrm{C}$ in China from 1951 to 2010

Figure 6 illustrates that the mean temperature in the hottest month showed a decreasing trend in the earlier three decades, while the mean temperature in the hottest month showed an increasing trend in the latter three decades for most parts of China. Therein, from the 1950 s to the 1970 s the regions that showed a decreasing trend were located in the Qinghai-Tibet Plateau and arid and semi-arid regions of northwest China. Similar to the accumulated temperature over $0^{\circ} \mathrm{C}$, from the 1980 s onward the area rate with increasing trend of mean temperature in the hottest month reached more than $60.0 \%$ of the whole of China. In the $1990 \mathrm{~s}$, the area rate was $86.2 \%$, and the northern regions across the Yangtze River basically maintained the increasing trend. Based on the 60 -year observation data, we also performed regression analysis. The linear trend results showed that $34.2 \%$ of the meteorological observation stations passed the significance test of increasing trend, while $31.9 \%$ of the meteorological observation stations passed the significance test of decreasing trend (Table 3).

To fully analyze the problem, the mean temperature in the coldest month was used to check the spatio-temporal change situation (Figure 7). In the 1960s, the area rate with increasing trend was less than $50.0 \%$, while the area rate reached $80.3 \%$ in the 1970 s. And from the $1980 \mathrm{~s}$ to the $1990 \mathrm{~s}$, the area rate with increasing trend continued to maintain a relatively high level. In the $2000 \mathrm{~s}$, the area rate dropped to $58.5 \%$. Figure 7 also illustrates the four different classes of values, which showed that the contour lines of mean temperature in the coldest month moved gradually northwards. In particular, the $0^{\circ} \mathrm{C}$ contour lines were found to be gradually approaching the Yellow River Basin from the Qinling Mountains and Huaihe River region. In that period, the regions with a decreasing trend were mainly distributed on the Northeast China Plain around Bohai Bay and in certain arid and semi-arid regions of northern China. Although there were some regions with a decreasing trend in China 


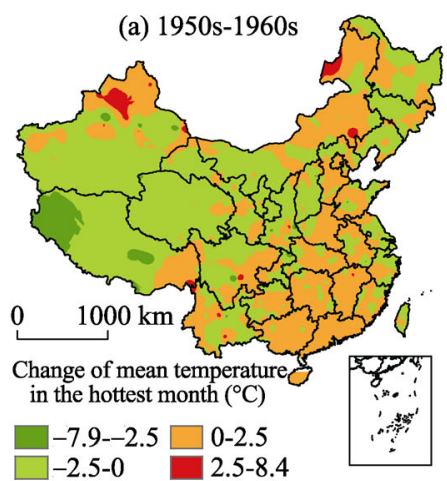

(d) $1980 \mathrm{~s}-1990 \mathrm{~s}$

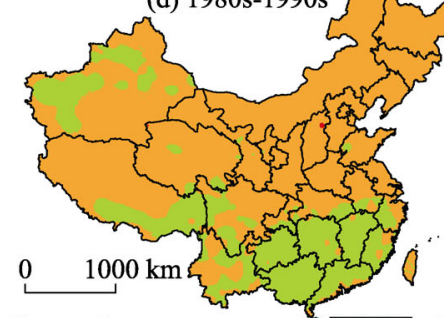

Change of mean temperature
in the hottest month $\left({ }^{\circ} \mathrm{C}\right)$

$-4.7--2.5 \square 0-2.5$

$-2.5-0 \quad 2.5-6.0$

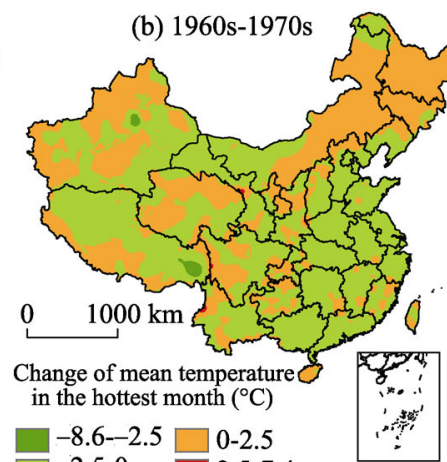

$-2.5-0=2.5-7.4$ (c) $1970 \mathrm{~s}-1980 \mathrm{~s}$

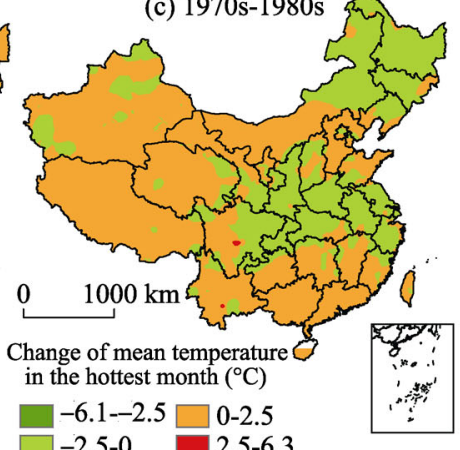

\section{(e) $1990 \mathrm{~s}-2000 \mathrm{~s}$}

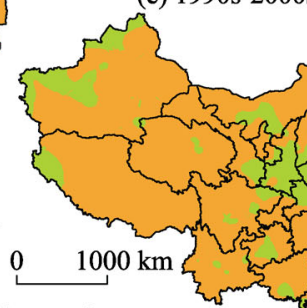

Change of mean temperature in the hottest month $\left({ }^{\circ} \mathrm{C}\right)$

$-4.3--2.5 \square 0-2.5$

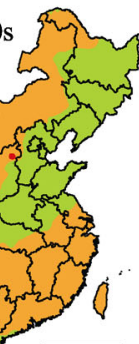

स्तुक्या:

, in.

Figure 6 Spatial changing trend of mean temperature in the hottest month in China from 1951 to 2010

(a) $1950 \mathrm{~s}-1960 \mathrm{~s}$

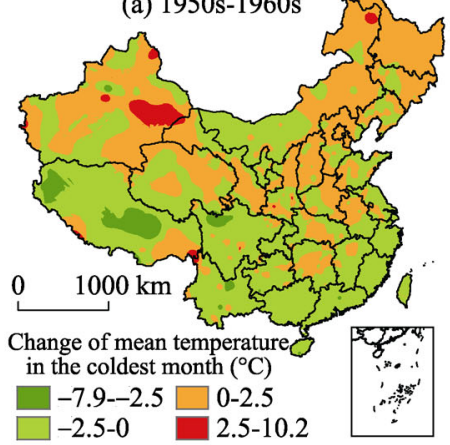

(d) $1980 \mathrm{~s}-1990 \mathrm{~s}$

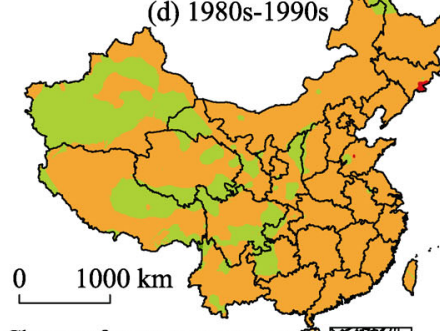

Change of mean temperature in the coldest month $\left({ }^{\circ} \mathrm{C}\right)$

$-6.9-2.5 \square 0-2.5$

$-2.5-0$

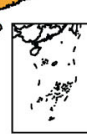

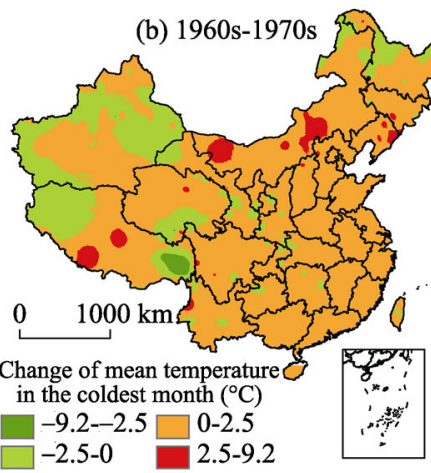

(e) $1990 \mathrm{~s}-2000 \mathrm{~s}$

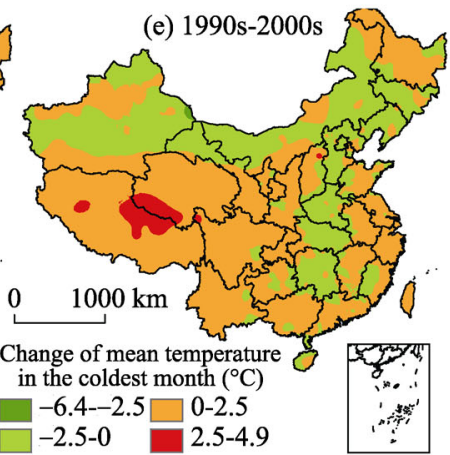

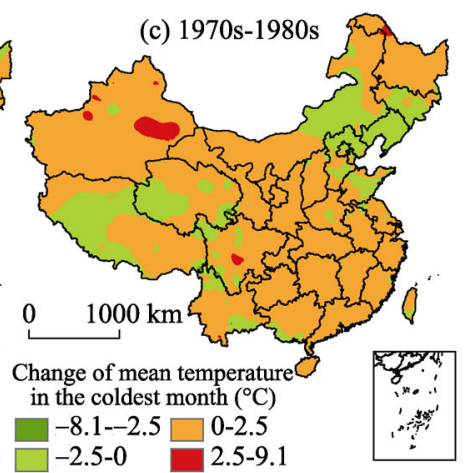

Figure 7 Spatial changing trend of mean temperature in the coldest month in China from 1951 to 2010 
in every decade, the areas with an increasing trend were always larger than the areas with a decreasing trend except for the first decade (the 1950s). The values of regression coefficients $b$ of 694 observation stations were greater than 0 and passed the significance test. Moreover, the analysis results showed that, in terms of spatial distribution, the mean temperature in the coldest month was different to the mean temperature in the hottest month in some regions of China (Table 3).

\subsection{Spatio-temporal changes in precipitation}

Precipitation is an important factor in agriculture. In this study, the spatial pattern of annual mean precipitation was mapped using the non-equal interval classification method (Figure 8). The northern borders of $200 \mathrm{~mm}$ contour lines of precipitation always varied along with the changes in the study period. The eastern borders of $400 \mathrm{~mm}$ contour lines of precipitation were found to have varied with time, while the southern borders remained stable, over the past 60 years. The borders of the $800 \mathrm{~mm}$ contour lines of precipitation also remained stable. The basic pattern of precipitation was stable, which led to a stable pattern of planting.

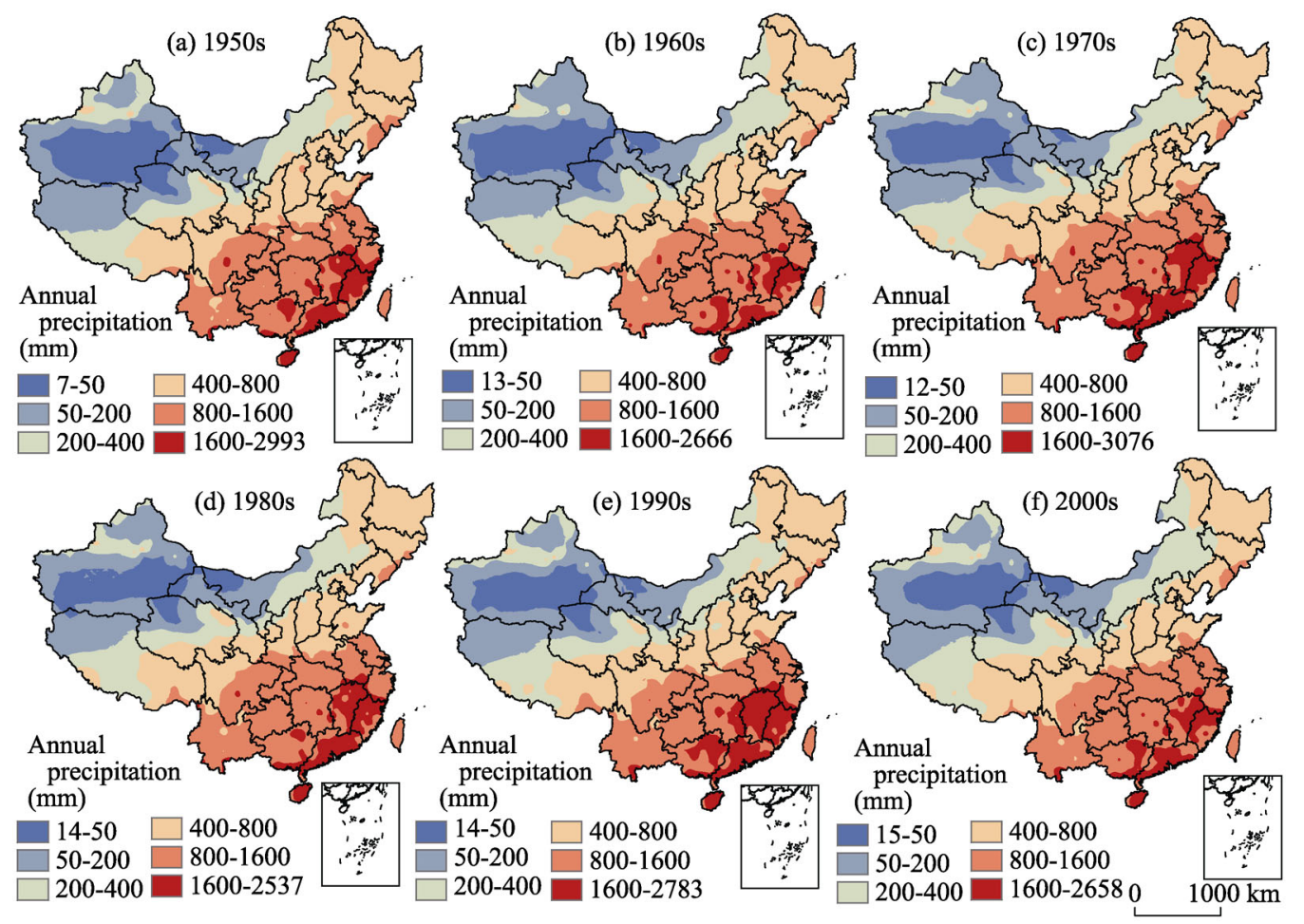

Figure 8 Spatial interpolation results of annual precipitation in China from 1951 to 2010

The spatial changes in precipitation over the six decades were analyzed by calculating the difference in results between one decade and the next (e.g. results for the 1960s minus results for the 1950s; results for the 2000s minus results for the 1990s; and so on) (Figure 9). The results showed that the maximum change areas occurred in southern China. In the 1950s-1960s and 1960s-1970s, the annual mean precipitation showed both an increasing trend and decreasing trend. In the $1970 \mathrm{~s}-1980$ s, the precipitation showed a decreasing trend 
in southern regions - in particular, the precipitation decreased by $100-800 \mathrm{~mm}$ in the Yunnan-Guizhou Plateau. In the 1980s-1990s, the annual mean precipitation showed an obviously increasing trend, while a relatively decreasing trend occurred in the $1990 \mathrm{~s}-2000 \mathrm{~s}$. The past 60 years have witnessed both increasing trends and decreasing trends in northeast China, north China, arid regions of northwest China, and the Qinghai-Tibet Plateau. The results of linear trend regression analysis showed that the trend values $b$ in most observation stations were less than 0 . But the results of the significance test revealed that $67.8 \%$ of the observation stations did not pass the significance test (Table 3). Therefore, there have been no obvious patterns of change in precipitation over the past 60 years. The change in precipitation was found to be more complex than the change in temperature factors.
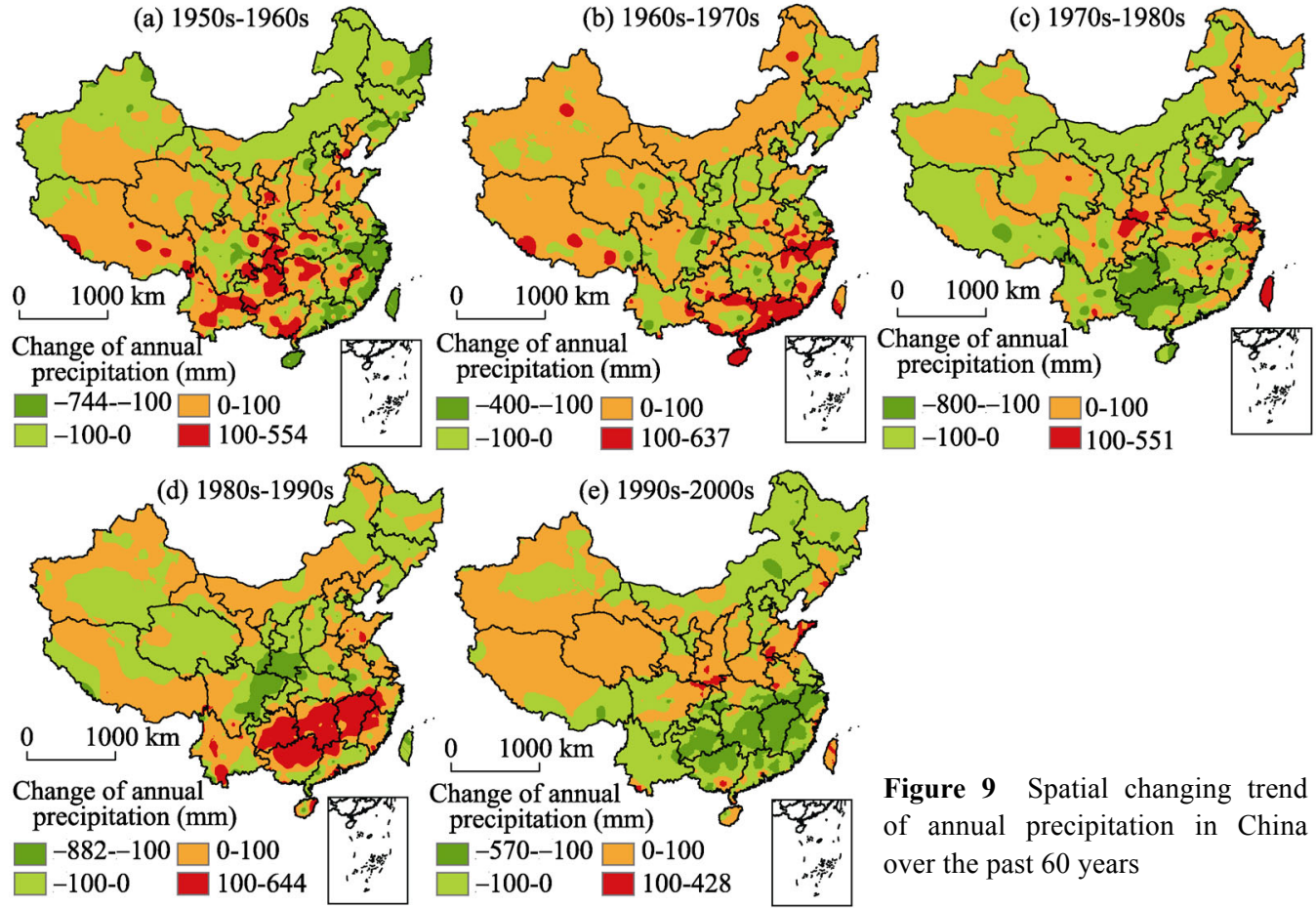

Figure 9 Spatial changing trend of annual precipitation in China over the past 60 years

\section{Discussion}

Almost all the agricultural heat resources-except the mean temperature in the hottest month-showed increasing trends over the past 60 years. By contrast, the agricultural water resource showed no significant pattern. It is likely that the impact of changes in agricultural water and heat conditions on agricultural production would vary owing to the different geographical locations, crop characteristics, and agronomic management systems. In the northeast region, increasing temperature significantly raised local heat resources, which would provide very suitable conditions for crop growth (Li et al., 2011). Overall, the heat resources showed an increasing trend in the northwest region, while an increasing trend of annual precipitation in the northwest region did not pass the significance test. However, these results may not be consistent with those found in other studies (Liu et al., 2005; Deng et al., 2010; Shi et al., 2002). Although higher temperatures can also accelerate field evapotranspiration, 
heat resources aid vegetation growth (Mamat et al., 2014). The increasing mean temperature in the coldest month may significantly reduce the ill-effects of low temperature on overwintering crops in northern China. Hu et al. found that winter wheat production increased along with increasing temperature in winter in northern China (Hu et al., 2014). Yet the decreasing mean temperature in the hottest month reduced the heat supply for thermophilic crops, and reduced the climatic suitability (Xu et al., 2014b). Most temperature factors continued to increase in southern regions. Temperature changes always shortened the growth season and reduced the amount of time available for accumulating nutrients. All these factors may influence crop quality and confer agricultural production risks (Yang et al., 2010). The heat resources showed an increasing trend, too, in the Qinghai-Tibet Plateau. In particular, the increasing accumulated temperature over $0^{\circ} \mathrm{C}$ made the region suitable for crop growth. Zhang et al. studied the plant density in the Yarlung Zangbo River Valley and found that warming temperatures expanded the areas of local vegetation growth (Zhang et al., 2013).

The aim of this study was to analyze the spatio-temporal changes in the hydrothermal conditions of agriculture over the past 60 years and discuss the effects of climate change on agricultural production. One main focus was an analysis of the spatio-temporal changes that have occurred in China. Previous studies have focused mainly on the impact of climate on agricultural production (Liu et al., 2005; Chen et al., 2006; Wei, 2007; Li et al., 2010; Tang and Yang, 2012; Hu et al., 2014; Qian et al., 2014; Xu et al., 2014b). Because of the limited range of the available analysis scales and methods, it was sometimes difficult to achieve consistent results. Based on a uniform standard, this study could provide more comprehensive analysis results. Another focus of the study was an analysis of the regional differences in climatic changes. Many previous researches have revealed that there is an increasing trend toward rising temperatures throughout China (Liu et al., 2005; Chen et al., 2006; Li et al., 2010; Dai et al., 2014; Hu et al., 2014; Qian et al., 2014). However, this study found that some heat factors may show a decreasing trend in some regions; for example, the mean temperature in the hottest month was reduced in most parts of two important agricultural regions: the Yellow River Basin and the Yangtze River Basin. At the same time, we also found that precipitation showed no significant change within the study period. Further research is needed to better understand the conclusion of "warm and humid" or "warm dry" conditions in certain regions (Liu et al., 2005; Li et al., 2010; Ren et al., 2014).

\section{Conclusions}

Based on the daily observation data from 824 meteorological stations in China, the paper analyzed the spatio-temporal changes in temperature and precipitation. The results showed the following:

(1) The $10^{\circ} \mathrm{C}$ contour lines moved towards high latitude in most northern regions and the low temperature areas rapidly diminished in the Qinghai-Tibet Plateau. The changing trend of annual mean temperature was significant and passed the 0.1 significance level test for the past 60 years. Similar to the changes in $10^{\circ} \mathrm{C}$ contour lines, the contour lines of accumulated temperature over $0^{\circ} \mathrm{C}$ moved towards high latitude since the $1960 \mathrm{~s}$, and the rising trend of accumulated temperature over $0^{\circ} \mathrm{C}$ passed the significance test for most conditions.

(2) The mean temperature in the hottest month showed two different trends in space, 
namely the coexistence of rising and falling trends. Therein, the areas with a significantly rising trend were mainly distributed in northeast China, the Inner Mongolia Plateau and southeast China, while the areas with a falling trend were distributed only in the middle and lower reaches of the Yellow River and the Yangtze River basins. The contour lines of mean temperature in the coldest month moved gradually northwards. In particular, the $0^{\circ} \mathrm{C}$ contour lines were close to the Yellow River Basin from the Qinling Mountains and Huaihe River region. The trend values of mean temperature in the coldest month were also positive for most parts of China.

(3) Although annual precipitation showed a decreasing trend in most areas, more than half of the observed stations did not pass the significance test. The $400 \mathrm{~mm}$ and $800 \mathrm{~mm}$ precipitation contour lines were the key rainfall factors for agricultural pattern, and the two key factors essentially remained stable, implying that stable boundaries existed between animal husbandry and planting, and between dryland farming and water farming. However, the precipitation contour lines of $200 \mathrm{~mm}$ and $1600 \mathrm{~mm}$ varied significantly in both northern and southern China.

During the period of whole crop growth, the influence of spatial distribution of temperature and precipitation on regional agriculture continued to vary owing to differences in regions and crop types. Future studies should explore the biological characteristics of one specific crop with its corresponding requirement for heat and water resources during the growth period. Then, we can quantitatively assess the effect of heat and water resources on crops and take measures to avoid certain harmful situations linked to specific climatic conditions.

\section{Acknowledgements}

The authors are grateful to the anonymous reviewers, who assisted with our research and provided constructive advice about the paper.

\section{References}

Alam M M, Siwar C, Jaafar A H et al., 2013. Agricultural vulnerability and adaptation to climatic changes in Malaysia: Review on paddy sector. Current World Environment, 8(1): 1-12.

Burton I, Huq S, Lim B et al., 2002. From impacts assessment to adaptation priorities: The shaping of adaptation policy. Climate Policy, 2: 145-159.

Chen H, Guo S L, Guo H J et al., 2006. Temporal and spatial trend in the precipitation and temperature from 1951 to 2003 in the Hanjiang basin. Resources and Environment in the Yangtze Basin, 15(3): 340-345. (in Chinese)

Dai S P, Li H L, Luo H X et al., 2014. The spatio-temporal change of active accumulated temperature $\geq 10^{\circ} \mathrm{C}$ in southern China from 1960 to 2011. Acta Geographica Sinica, 69(5): 650-660. (in Chinese)

Deng Z Y, Zhang Q, Ning H F et al., 2010. Influence of climate warming and drying on crop eco-climate adaptability in northwestern China. Journal of Desert Research, 30(3): 633-639. (in Chinese)

Ding Y H, Zhang J, Xu Y et al., 2003. Climatic System Change and Forecast. Beijing: China Meteorological Press, 32-35. (in Chinese)

Dong X G, Gu W Z, Meng X X et al., 2014. Change features of precipitation events in Shandong Province from 1961 to 2010. Acta Geographica Sinica, 69(5): 661-671. (in Chinese)

Edmar I T, Guenther F, Harrij V V et al., 2013. Global hot-spots of heat stress on agricultural crops due to climate change. Agriculture and Forest Meteorology, 170: 206-215.

Falloon P, Betts R, 2010. Climate impacts on European agriculture and water management in the context of adaptation and mitigation: The importance of an integrated approach. Science of the Total Environment, 408: 5667-5687.

Fernanda M S, Maria L F, 2009. Climate change and its marginalizing effect on agriculture. Ecological Econom- 
ics, 68: 896-904.

Han L Y, Zhang Q, Yao Y B et al., 2014. Characteristics and origins of drought disasters in Southwest China in nearly 60 years. Acta Geographica Sinica, 69(5): 632-639. (in Chinese)

He H Y, Guo Z H, Xiao W F, 2005. Review on spatial interpolation techniques of rainfall. Chinese Journal of Ecology, 24(10): 1187-1191. (in Chinese)

$\mathrm{Hu}$ S, MO X G, Lin Z H, 2014. The contribution of climate change to the crop phenology and yield in Haihe River Basin. Geographical Research, 33(1): 3-12. (in Chinese)

Ji Q, Yu M, 2010. Study on parameters setting of ordinary cokriging interpretation to average annual temperature. Journal of Capital Normal University (Natural Science Edition), 31(4): 81-87. (in Chinese)

Li Y, Yang X G, Wang W F et al., 2010. Changes of China agricultural climate resources under the background of climate change I: Spatiotemporal change characteristics of agricultural climate resources in South China. Chinese Journal of Applied Ecology, 21(10): 2605-2614. (in Chinese)

Li Y C, He Z M, Liu C X, 2014. Review on spatial interpolation methods of temperature data from meteorological stations. Progress in Geography, 33(8): 1019-1028. (in Chinese)

Li Z G, Yang P, Tang H J et al., 2011. Trend analysis of typical phenophases of major crops under climate change in the three provinces of Northeast China. Scientia Agricultura Sinica, 44(20): 4180-4189. (in Chinese)

Liu D X, Dong A A, Lu D R, 2005. Climatic change of Northwest China and its influence on agricultural production in recent 43 years. Agricultural Research in the Arid Area, 23(2): 195-201. (in Chinese)

Liu Y L, Yan J P, Cen M Y, 2015. Comprehensive evaluation of precipitation heterogeneity in China. Acta Geographica Sinica, 70(3): 392-406. (in Chinese)

Ma X, Wu S H, Li Y E et al., 2012. Assessing climate change impact on seasonal drought in main rice cropping regions in the south of China. Acta Geographica Sinica, 67(11): 1451-1460. (in Chinese)

Mamat Y, Ulam M, Sabit M, 2014. Impact of climate warming on cotton production of Ugan-Kuqa River delta oasis. Geographical Research, 33(2): 251-259. (in Chinese)

Olesen J E, Bindi M, 2002. Consequences of climate change for European agricultural productivity, land use and policy. European Journal of Agronomy, 16: 239-262.

Piao S L, Ciais P, Huang Y et al., 2010. The impacts of climate change on water resources and agriculture in China. Nature, 467: 43-51.

Qian J X, Li N, Han P, 2014. Influence of climate warming in winter on the winter wheat cultivable area in Shanxi Province. Acta Geographica Sinica, 69(5): 672-680. (in Chinese)

Ragab R, Prudhomme C, 2002. Climate change and water resources management in arid and semi-arid regions: Prospective and challenges for the 21st century. Biosystems Engineering, 81(1): 3-34.

Ramirez-Villegas J, Jarvis A, Läderach P, 2013. Empirical approaches for assessing impacts of climate change on agriculture: The EcoCrop model and a case study with grain sorghum. Agricultural and Forest Meteorology, 170: 67-78.

Ren Z G, Zhang M J, Wang S J et al., 2014. Changes in precipitation extremes in South China during 1961-2011. Acta Geographica Sinica, 69(5): 640-649. (in Chinese)

Shi Y F, Shen Y P, Hu R J, 2002. Preliminary study on signal, impact and foreground of climatic shift from warm-dry to warm-humid in Northwest China. Journal of Glaciology and Geocryology, 24(3): 219-226. (in Chinese)

Smith W N, Grant B B, Desjardins R L et al., 2013. Assessing the effects of climate change on crop production and GHG emissions in Canada agriculture. Ecosystems and Environment, 179: 139-150.

Tang G A, Yang X, 2012. ArcGIS: GIS Spatial Analysis Experiment Tutorial. Beijing: Science Press. (in Chinese)

Tao F L, Zhang S, Zhang Z, 2012. Spatiotemporal changes of wheat phenology in China under the effects of temperature, day length and cultivar thermal characteristics. European Journal of Agronomy, 43: 201-212.

Wei F Y, 2007. Modern Climate Statistics Diagnosis and Prediction Technology. Beijing: China Meteorological Press. (in Chinese)

Xiong W, Yang J, Wu W B et al., 2013. Sensitivity and vulnerability of China's rice production to observed climate change. Acta Ecologica Sinica, 33(2): 509-518. (in Chinese)

Xu J W, Ju H, Liu Q et al., 2014. Variation of drought and regional response to climate change in Huang-Huai-Hai Plain. Acta Ecologica Sinica, 34(2): 460-470. (in Chinese)

Xu L L, Lv H Q, Fang L, 2014. Effect of climate change on the climate suitability of summer maize on the Huang-Huai-Hai Plain. Resources Science, 36(4): 782-787. (in Chinese)

Yang S B, Shen S H, Zhao X Y et al., 2010. Impacts of climate changes on rice production in the middle and lower reaches of the Yangtze River. Acta Agronomica Sinica, 36(9): 1519-1528. (in Chinese)

Zhang G L, Dong J W, Zhou C P et al., 2013. Increasing cropping intensity in response to climate warming in Tibetan Plateau, China. Field Crops Research, 142: 36-46. 